Jurnal Natur Indonesia 14(1), Oktober 2011: 37-41

ISSN 1410-9379, Keputusan Akreditasi No 65a/DIKTI/Kep./2008

\title{
Enzyme-Catalysed Synthesis of Palm-Based Wax Esters-A Kinetic Study
}

\author{
Erin Ryantin Gunawan ${ }^{1^{*}}$, Mahiran Basri ${ }^{2)}$ and Dedy Suhendra ${ }^{1)}$ \\ ${ }^{1)}$ Department of Chemistry, Faculty of Mathematics and Natural Sciences, University of Mataram, Mataram 83125 \\ ${ }^{2}$ Enzyme and Microbial Technology Research, Faculty of Science and Environmental Studies, Malaysia 43400
}

Diterima 17-08-2009 Disetujui 18-02-2011

\begin{abstract}
Wax esters are long chain esters that are derived from fatty acids and alcohols with chain lengths of 12 carbons or more. Wax esters have a wide range of application in industrial especially in cosmetics. The present work focuses on the synthesis of wax esters by alcoholysis reaction from palm oil and oleyl alcohol in hexane by lipase from Rhizomucor meihei (Lipozyme IM). Effect of various concentrations of palm oil and oleyl alcohol were studied to deduce the kinetics and mechanism of the reaction. The alcoholysis reaction followed MichaelisMenten kinetics. The reaction follows a Ping-pong Bi-Bi mechanism. The maximum rate was estimated to be $6 \times 10^{-3} \mathrm{mmol} / \mathrm{h}$. mg catalyst and the Michaelis-Menten constant for palm oil and oleyl alcohol were $4.145 \mathrm{M}$ and $6.120 \mathrm{M}$, respectively.
\end{abstract}

Keywords: alcoholysis, lipase, oleyl alcohol, palm oil, wax esters

\section{INTRODUCTION}

Interest in lipase-catalyzed preparation of wax esters has grown in the last decade, because of the ability to obtain a wide variety of high-quality products under mild reaction condition (Mat Radzi et al. 2005; George et al. 2000). Wax esters consist of a long fatty acid esterified to a long alcohol. Wax esters are important ingredients in cosmetic formulations (cleansers, conditioners and moisturizers) (Peter \& Robert 2001), in pharmaceuticals (as an anti foaming agent in the production penicillin and a timed release in the production pharmaceutical tablet) (Kline 1956), lubricants, plasticizers and polishes (Chen \& Wang 1997).

Wax esters can be extracted from animals and plant materials such as beeswax, sperm whale and jojoba oil. However, it is often either too scarce or expensive for commercial use and the main obstacles to large-scale use them are its availability (Sanchez et al. 1992; Yadav \& Lathi 2003). The synthetic wax esters can be synthesized using chemicals and enzymatic catalyzed methods (Gunawan \& Suhendra 2008a, 2008b). The use of homogeneous chemical catalysts leads to several problems such as corrosion of equipment, hazards of handling of the corrosive acids, highenergy consumption and degradation of esters, (Knox \& Clife 1984), whereas the enzymatic synthesis offers mild reaction conditions and environmentally friendly process.

We have optimized the lipase-catalyzed alcoholysis of palm-based wax ester and oleyl alcohol (Gunawan \& Suhendra 2008a, 2008b). In the present study, the kinetics of the alcoholysis of palm oil and oleyl alcohol in hexane, catalyzed by lipozime IM was examined. This study is for understanding the reaction mechanism, as well as for design of alcoholysis reactor for scale-up.

\section{MATERIALS AND METHODS}

Immobilized lipase from Mucor miehei (Lipozyme) was produced by Novo Nordisk (Denmark). Palm oil (MW=3 x average of saponification equivalent of palm oil) was obtained from Southern Edible Oil Sdn. Bhd. (Malaysia). Fatty acid composition of Malaysia palm oil are $0.1-0.3 \%$ of lauric acid, $0.9-1.5 \%$ of myristic acid, $39.2-45.2 \%$ of palmitic acid, $3.7-5.1 \%$ of stearic acid, $37.5-44.1 \%$ of oleic acid and $8.7-12.5 \%$ of linoleic acid (PORIM 1986). Oleyl alcohol was obtained from Fluka Chemika (Switzerland). Ester standards, oleyl laurate, oleyl myristate, oleyl palmitate, oleyl stearate, oleyl oleate, oleyl linoleate and methyl linoleate were obtained from Sigma Aldrich (USA). Hexane was obtained from J.T. Baker (USA). All other chemicals were of analytical grade.

Kinetic study. The initial rates in the presence of different concentrations of substrates were studied. Two sets of reaction mixture were used to determine the initial reaction rate i.e. 1) the reaction mixtures containing different concentrations of palm oil with a constant concentration of oleyl alcohol, and 2) the reaction mixtures containing different concentration of oleyl alcohol with a constant concentration of palm oil. The reaction sets were 
incubated in water bath shaker at $40^{\circ} \mathrm{C}$ for $3 \mathrm{~h}$ with shaking speed $150 \mathrm{rpm}$.

The initial rates were estimated from the slope of plots of the percentage conversion versus reaction period and reported as mg/h.mg catalyst. The maximum initial rate $\left(v_{\max }\right)$ and Michaelis-Menten constants $\left(K_{\mathrm{m}}\right)$ were determined by linear regression using the Lineweaver-Burk approach.

Synthesis and Analysis. Different molar ratios of palm oil and oleyl alcohol were added to $10 \mathrm{ml} n$-hexane, followed by amounts of enzyme. The mixture of palm oil, oleyl alcohol and Lipozyme I M were incubated in a horizontal water bath shaker $(150 \mathrm{rpm})$ at different reaction temperatures and reaction times. The reactions were analyzed by a gas chromatograph (Hitachi model G-3000, Tokyo, Japan), using an Rtx-65TG capillary column (30 m x $0.25 \mathrm{~mm}$ ). Helium was used as the carrier gas at a flow rate $30 \mathrm{ml} / \mathrm{min}$. The temperature was programmed at $2 \mathrm{~min}$ at $150^{\circ} \mathrm{C}, 20^{\circ} \mathrm{C} / \mathrm{min}$ to $300^{\circ} \mathrm{C}$ and $10 \mathrm{~min}$ at $300^{\circ} \mathrm{C}$. The product composition was quantitated by an internal standard method with methyl linoleate as the internal standard. The concentrations of esters were calculated by equation: $\mathrm{C}_{\mathrm{x}}=\left(\mathrm{A}_{\mathrm{x}} / \mathrm{A}_{\mathrm{IS}}\right) \mathrm{x}\left(\mathrm{C}_{\mathrm{IS}} \mathrm{xD} \mathrm{Df} \mathrm{IS}_{\mathrm{Rfx}} / \mathrm{D}_{\mathrm{x}}\right)$, where $\mathrm{C}$ is the amount of component $\mathbf{x}$ or internal standard, $\mathrm{A}$ is area for component $\mathbf{x}$ or internal standard and $\mathrm{D}_{\mathrm{Rf}}$ is detector response factor for component $\mathbf{x}$ or internal standard $\left(D_{\mathrm{Rf}}=A_{\mathbf{x}} / \mathrm{C}_{\mathbf{x}}\right.$ and $\mathrm{D}_{\mathrm{Rf}}$ $\left.{ }_{\mathrm{IS}}=\mathrm{A}_{\mathrm{IS}} / \mathrm{C}_{\mathrm{IS}}\right)$. The percentage yield of ester was calculated by equation: Percentage Yield $(\%)=(\mathrm{mmol}$ ester $/ \mathrm{mmol}$ palm oil used) $\mathrm{x} 100 \%$.

\section{RESULTS AND DISCUSSION}

Kinetic is a study concerning with the rates at which reactions occur and with the factors that affect the rates of a reaction, such as $\mathrm{pH}$, temperature, presence of catalyst, and is therefore essential in an experimental investigation. The interpretation of the kinetic results obtained for a chemical reaction and their dependence on other factors can lead to understanding of the mechanism of the reaction.

The study of the kinetics of Lipozyme IM catalyzed synthesis of esters from the reaction of oleyl alcohol and palm oil was best achieved by measuring the initial rate in the presence of different concentrations of substrate. The effect of reaction parameters on initial reaction rate $(v)$ was studied. Figures 1 shows the relationship of the initial rate of alcoholysis as a function of concentration of palm oil at various fixed concentrations of oleyl alcohol. For alcoholysis reactions, as can be seen from the hyperbolic curves, the reaction follows Michaelis-Menten type kinetic, further confirming that the enzymatic reaction is kinetically controlled. The initial reaction rate increased and reached a maximum at the concentrations palm oil of about $2 \mathrm{mmol}$, at all fixed oleyl alcohol concentrations.

A similar trend was observed on the dependence of the initial reaction rate of the alcoholysis on oleyl alcohol concentrations of several palm oil concentrations tested (Figure 2).

The initial reaction rate increased with the increase in oleyl alcohol concentration and reached a maximum at a concentration of $3 \mathrm{mmol}$ of palm oil, then decreased above this concentration. Although this behavior would be expected for the chemical equilibrium of the species, the decrease observed indicates the possibility of inhibition effects due to the concentration of both species on the catalytic function of the enzyme (Zaidi et al. 2002).

Interpretation of the kinetics of most enzyme-catalyzed synthetic reactions is hampered because the behavior

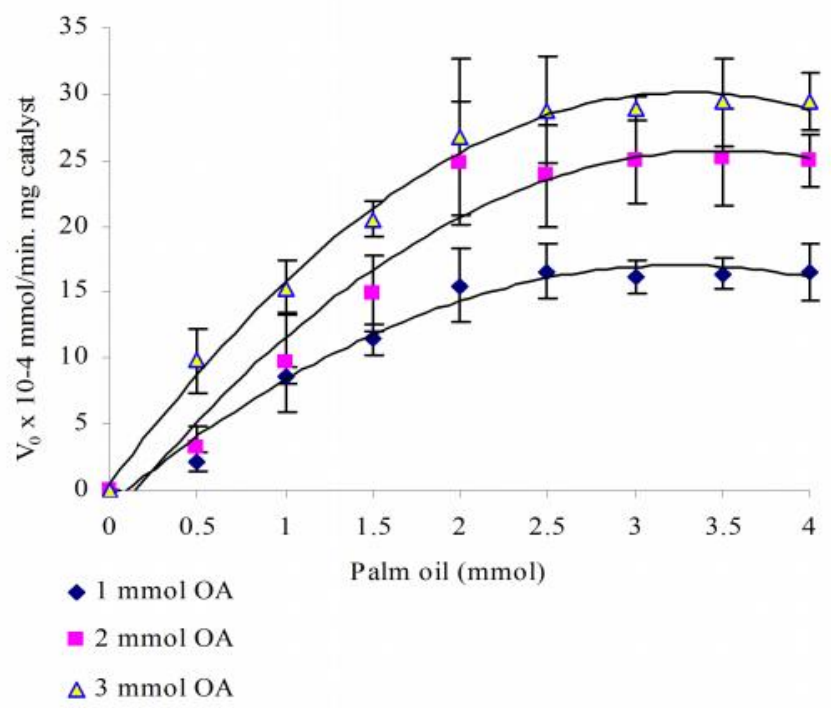

Figure 1 Initial reaction rate of alcoholysis as a function of palm oil concentration $\left(\mathrm{OA}=\right.$ Oleyl alcohol, $\mathrm{V}_{0}=$ initial rate $)$

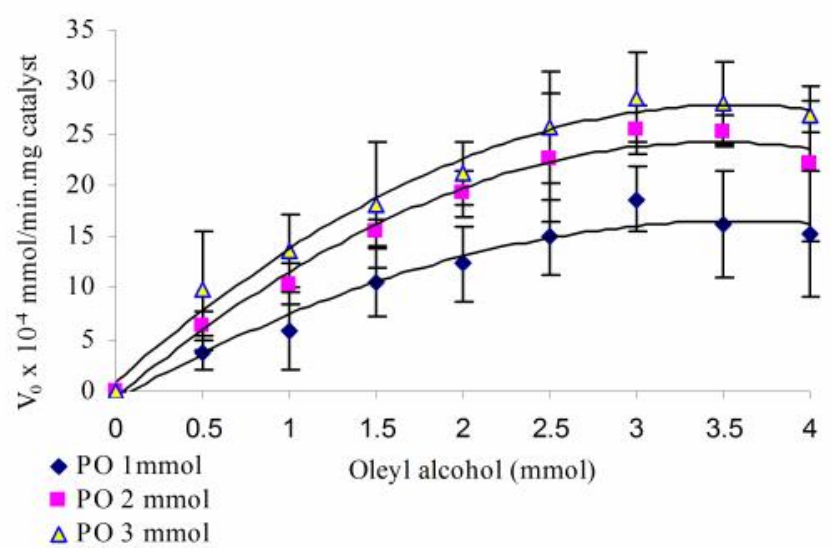

Figure 2 Initial reaction rate of palm oil (PO) alcoholysis as a function of oleyl alcohol concentration $\left(\mathrm{V}_{0}=\right.$ initial rate $)$ 
predicted by a mathematical formula is only valid in an ideal system in which the concentration of both substrates is small. However, the enzymatic catalysis of two substrates can be simplified by maintaining the concentration of one substrate, and a plot of initial rate against the other substrate concentration will follow a Michaelis-Menten type relationship (Lai et al. 1999).

The maximum initial rate of substrates consumption $\left(v_{\max }\right)$ and Michaelis-Menten constants $\left(K_{\mathrm{m}}\right)$ were determined by linear regression using the Lineweaver-Burk approach. The $v_{\max }$ and $K_{\mathrm{m}}$ are two important kinetic parameters, which are useful for describing the properties of an enzyme-catalyzed reaction. $v_{\max }$ is the maximum velocity or limiting rate; $K_{\mathrm{m}}$ is the Michaelis constant Mathematically, the Michaelis-Menten equation can be written as follows: (Robert 1977).

$v=\frac{v_{\max }[S]}{K_{m}+[S]}$

where $[\mathrm{S}]$ denotes the substrate concentration. The Michaelis-Menten equation can be modified to linear regression equation, which is known as Lineweaver-Burk equation.

$$
\frac{1}{v}=\left(\frac{K_{m}}{v_{\max }}\right) \frac{1}{[S]}+\frac{1}{v_{\max }}
$$

A Lineweaver-Burk (double-reciprocal) plot (Figure 3 and 4) can be further used to generate plots of the dependency of the values of the intercept for the different concentrations of oleyl alcohol to yield the values of $\mathrm{K}_{\mathrm{m}}$ (slope) and $V_{\max }$ (intercept). The estimated parameter values are summarized in Table 1. Similar maximum rate values were obtained in this research. Awang et al. (2004), have also reported a similar observation, on the esterification of palm-based 9,10-dihydroxystearic acid and 1-octanol.

Given the nature of enzyme-catalyzed reactions, the case of a single product reaction is very rare. Most cases of enzyme-catalyzed reactions involve more than one substrate and produce two or more products (Lai et al. 1999). The alcoholysis of palm oil with oleyl alcohol can be considered in this research as an enzymatic reaction system, which involves two reactants and two products. There are three possibilities of enzymatic reaction mechanisms that involve two reactants and two products: 1) a random-order

Table 1 Kinetic and thermodynamic parameters for the alcoholysis of palm oil and oleyl alcohol

\begin{tabular}{lcc}
\hline \multicolumn{1}{c}{ Substrate } & $\mathrm{K}_{\mathrm{m}}(\mathrm{mmol})$ & $\mathrm{V}_{\max .}(\mathrm{mmol} / \mathrm{h} . \mathrm{mg}$ catalyst $)$ \\
\hline Palm oil & 4.145 & $5.94 \times 10^{-3}$ \\
Oleyl alcohol $^{*}$ & 6.120 & $6.03 \times 10^{-3}$ \\
\hline
\end{tabular}

mechanism, 2) a ping-pong mechanism, and 3) an ordered bi-bi mechanism. Scheme 1 shows the general reaction schemes for the three possibilities. According to the studies of some researchers about inter-esterification and trans-esterification(Garcia et al. 1999; Zaidi et al. 2002), the active conformation of lipase comes via an acyl-enzyme intermediate. Since the reaction sequence must be initiated with the bond formation between the carboxyl groups, the random mechanism can be considered less likely.

Based on the type of substrates, the most appropriate explanation for the lipase catalysis mechanism is ping-pong mechanism and ordered bi-bi mechanism, which involve acyl-enzyme intermediate.

Lai et al. (1999), combine these mechanisms to be pingpong bi-bi (i.e., bi-substrate, bi-product, non-sequential kinetics) mechanism, in which the first reactant would be involved in the reaction mechanism producing the

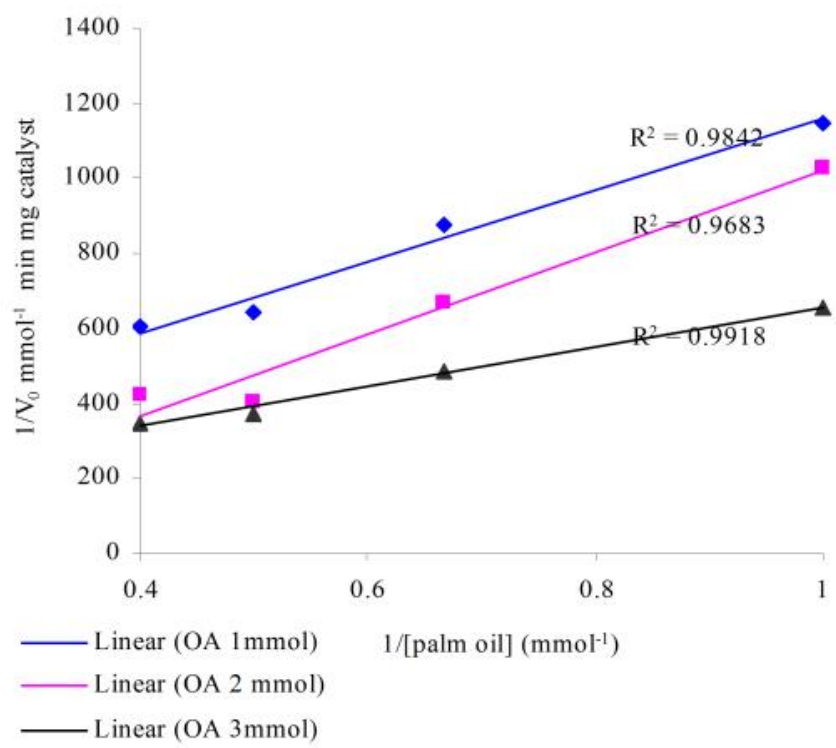

Figure 3 Lineweaver-Burk plot of alcoholysis of palm oil as a function of palm oil concentration $\left(\mathrm{OA}=\right.$ Oleyl alcohol, $\mathrm{V}_{0}=$ initial rate)

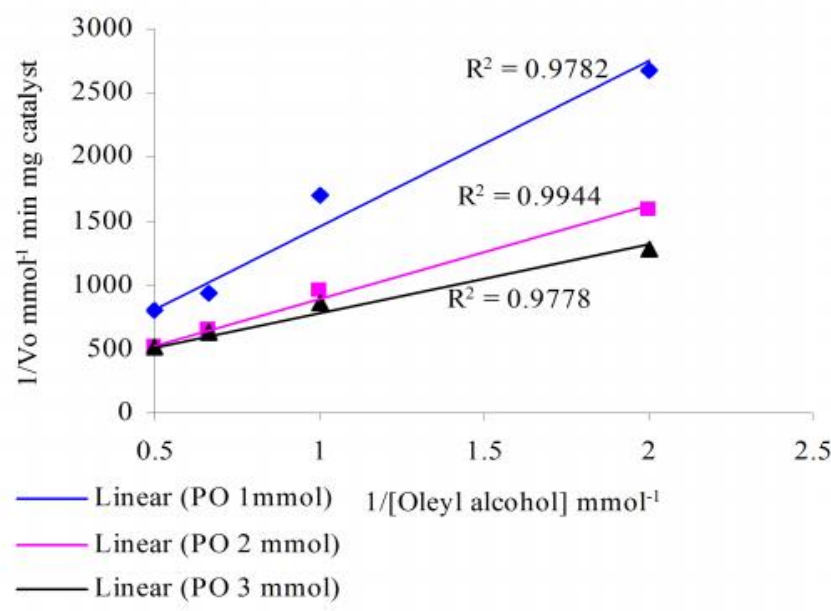

Figure 4 Lineweaver-Burk plot of palm oil (PO) alcoholysis as a function of oleyl alcohol concentration $\left(\mathrm{V}_{0}=\right.$ initial rate $)$ 
active enzyme-reactant complex; in the next step, the second reactant would be incorporated to form the ternary complex first reactant-enzyme-second reactant followed by the chemical reaction step, i.e. the transformation of the ternary complex into first product-enzyme-second product complex. In the next step, the first product molecule would be released followed afterwards by the second. Salis et al. (2003), suggested that in alcoholysis of tryglycerides (TGs)

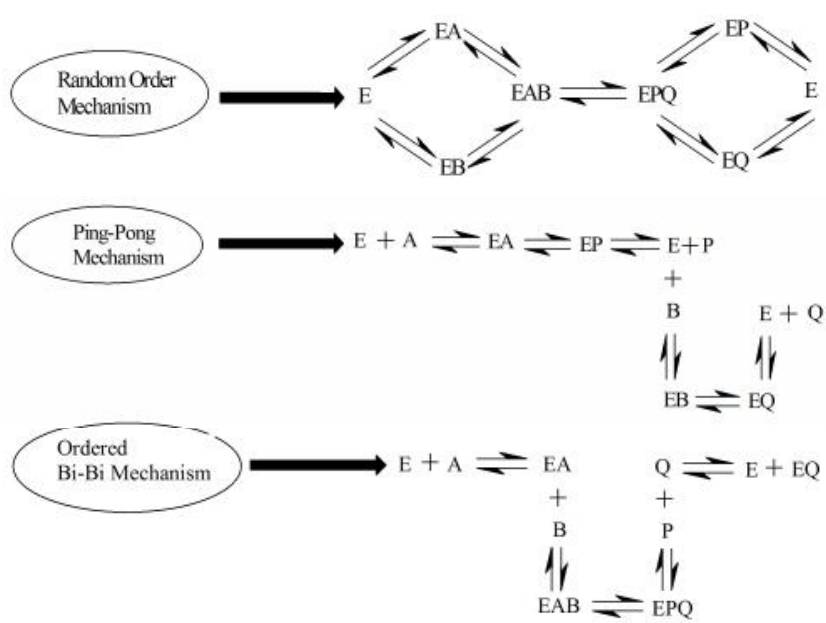

Scheme 1 Possible enzymatic reaction mechanisms; $\mathrm{A}$ is substrate A, $\mathrm{B}$ is substrate $\mathrm{B}, \mathrm{E}$ is enzyme, $\mathrm{EA}, \mathrm{EB}$ or $\mathrm{EAB}$ is complex of enzyme-substrates, EPQ is complex enzyme-product-water, EQ is complex enzyme-water, EP is complex enzymeproduct
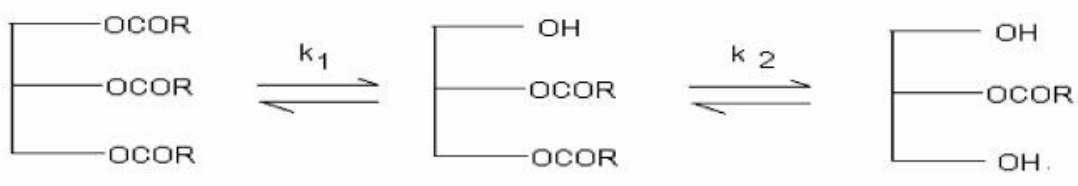

TG
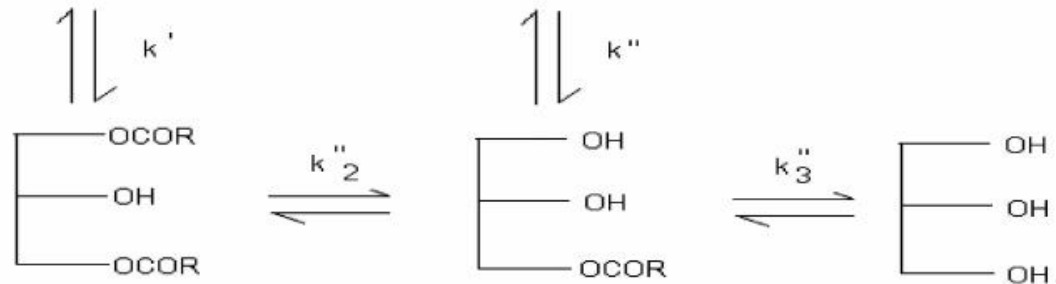

Scheme 2 Catalyzed of tryglycerides alcoholysis processes (Salis et al. 2003). Enzymatic action of Lipozyme RMIM
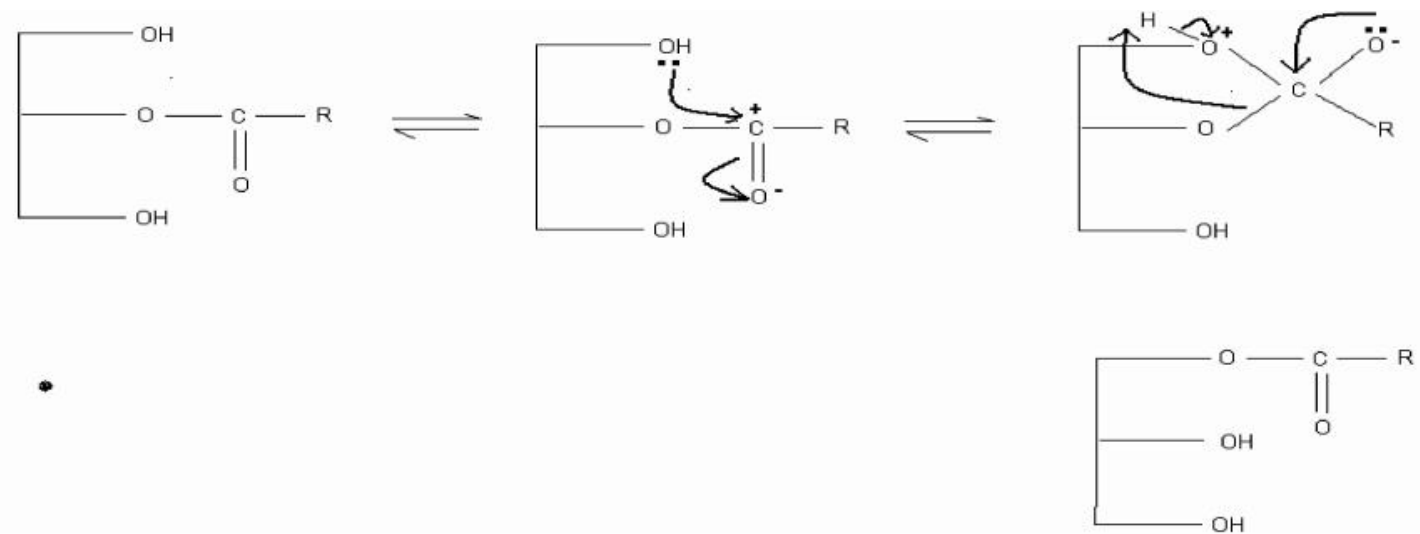

Scheme 3 Catalyzed of tryglycerides alcoholysis processes (Salis et al. 2003). acyl migration process 


\section{REFFERENCES}

Awang, R., Basri, M., Ahmad, S. \& Salleh, A.B. 2004. Lipasecatalyzed esterification of palm-based 9,10-dihydroxystearic acid and 1-octanol in hexane- a Kinetic study. Biotechnology Letters 26: 11-14.

Chen, J.P. \& Wang, J.B. 1997. Wax ester synthesis by lipasecatalyzed esterification with fungal cells immobilized on cellulose biomass support particles. Enzyme and Microbial Technology 18: 615-622.

Garcia, T., Sanchez, N., Martinez, M. \& Aracil, J. 1999 Enzymatic synthesis of fatty esters part II, Optimization studies, Enzyme and Microbial Technology 25: 591-597

George, S., Kichhorff, R. \& Mukherjee, K.D. 2000. Lipase catalyzed alcoholysis of crambe oil and camelina oil for The preparation of long-chain esters, Journal of American oilChemistry Society 61(2): 191-195

Gunawan, E.R. \& Suhendra, D. 2008a. Four-factor response surface optimization of the enzymatic synthesis of wax ester from palm kernel oil. Indonesian Journal of Chemistry 8(1): $83-90$

Gunawan, E.R. \& Suhendra, D. 2008b. Wax ester production by alcoholysis of palm oil fractions. Indonesian Journal of Chemistry 8(3): 356-362.

Kline, S. 1956. French international co, improvements in or relating to pharmaceutical tablet or pellet and method of preparing the same, GB 747914.

Knox, T. \& Cliffe, K.R. 1984. Synthesis of long-chain esters in a loop reactor system using a fungal cell bound enzyme, Process Biochemistry 19: 188-192.

Lai, D.T., Hattori, N. \& O'connor, J. 1999. Kinetics of enzymatic synthesis of isopropylidene glycerol ester by goat pregastric lipase, Journal of American Oil Chemists' Society 76(7): 845851
Mat Radzi, S., Basri, M., Salleh, A.B. \& Abdurrahman, M.B. 2005. Large scale production of liquid wax ester by immobilized lipase, Journal of Oleo Science 54: 203-209.

Peter, T.R. \& Robert, B. 2001. Beeswax through the ages.Personal Care. Oct 27-31.

PORIM Technology 16. 1986. Malaysian palm kernel stearin. Palm Kernel Olein and Their hydrogenated products. Bangi: Palm Oil Research Institute Malaysia. 1-9.

Roberts, D.V. 1977. Enzyme Kinetics, London: Cambridge University Press.

Salis, A., Solinas, V. \& Monduruzzi, M. 2003. Wax ester synthesis from heavy fraction of sheep milk fat and cetyl alcohol by immobilised lipases. Journal of Molecular Catalysis. B: Enzymatic 21: 167-174.

Sanchez, N., Martinez, M.J., Aracil \& Corma, A. 1992. Synthesis of oleyl oleate as jojoba oil analog. Journal of American Oil Chemists' Society 69: 1150-1153.

Yadav, G.D. \& Lathi, P.S. 2003. Kinetics and mechanism of synthesis of butyl isobutyrate over immobilised lipases. Biochemistry Engineering Journal 16: 245-252

Zaidi, A., Gainer, J.L., Carta, G. \& Mrani, A. 2002. Esterification of fatty acids using nylon-immobilized lipase in $n$-hexane: kinetic parameters and chain length effects. Journal of Biotechnology 93: 209-216. 